\title{
Efficacy and Tolerability of High-Flow Nasal Cannula Oxygen Therapy for Hypoxemic Respiratory Failure in Patients with Interstitial Lung Disease with Do-Not-Intubate Orders: A Retrospective Single-Center Study
}

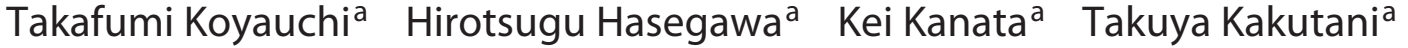 \\ Yusuke Amano $^{a}$ Yuichi Ozawa $^{a}$ Takashi Matsui $^{a}$ Koshi Yokomura ${ }^{a}$ \\ Takafumi Sudab \\ a Department of Respiratory Medicine, Respiratory Disease Center, Seirei Mikatahara General Hospital, Hamamatsu,

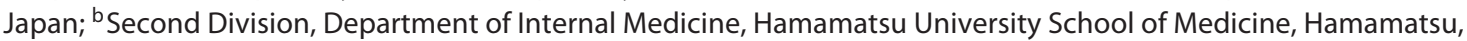 \\ Japan
}

\section{Keywords}

High-flow nasal cannula oxygen therapy · Interstitial lung disease · Idiopathic pulmonary fibrosis - Do-not-intubate order · Palliative care

\footnotetext{
Abstract

Background: High-flow nasal cannula (HFNC) oxygen therapy may provide effective respiratory management of hypoxemic respiratory failure in patients with interstitial lung disease (ILD) with a do-not-intubate (DNI) order. Objectives: The aim was to assess the efficacy and tolerability of HFNC for these patients. Methods: We retrospectively reviewed the records of patients requesting a DNI order for hypoxemic respiratory failure associated with ILD, comparing treatment with HFNC and noninvasive positive pressure ventilation (NPPV). Outcomes measured were 30-day survival, in-hospital mortality, temporary interruption and discontinuation of the treatment at the patient's request, adverse events, oral
}

intake, and communication ability at the end of life. Results: A total of 84 patients (HFNC, $n=54$; NPPV, $n=30$ ) were analyzed. Neither 30 -day survival (HFNC $31.5 \%$ vs. NPPV $30.0 \%$; $p=0.86$ ) nor in-hospital mortality (HFNC $79.6 \%$ vs. NPPV $83.3 \% ; p=0.78$ ) differed significantly. The temporary interruption and discontinuation rates were significantly lower in the HFNC group than in the NPPV group (3.7 vs. $23.3 \%$; $p=$ 0.009 and 0 vs. $10 \% ; p=0.043$, respectively), and that group had significantly fewer adverse events. Among patients who died in the hospital, those treated with HFNC had significantly better oral intake and ability to converse until just before death. Conclusion: HFNC had a survival rate equivalent to that of NPPV and was better tolerated by patients with hypoxemic respiratory failure associated with ILD who had a DNI order. HFNC allowed patients to eat and converse until just before death, suggesting that HFNC in these patients is a reasonable palliative treatment.

(c) 2018 S. Karger AG, Basel

\section{KARGER}

(c) 2018 S. Karger AG, Basel

E-Mail karger@karger.com

www.karger.com/res
Takafumi Koyauchi, MD

Department of Respiratory Medicine, Respiratory Disease Center Seirei Mikatahara General Hospital

3453 Mikatahara, Kita-ku, Hamamatsu, Shizuoka 433-8558 (Japan)

E-Mail tak.koyauchi@outlook.jp 


\section{Introduction}

High-flow nasal cannula (HFNC) oxygen therapy can decrease dead space ventilation, improve oxygenation, and reduce dyspnea by supplying oxygen at a high rate of flow. Among patients with acute hypoxemic respiratory failure, the use of HFNC is associated with rates of intubation and death equivalent to rates with commonly used conventional oxygen therapy and noninvasive positive pressure ventilation (NPPV) [1-3]. In addition, HFNC has characteristics that greatly contribute to maintaining a better quality of life (QOL), such as allowing oral intake, oral care, and conversation.

Interstitial lung disease (ILD), including idiopathic pulmonary fibrosis (IPF), is a chronic progressive disease which usually increases in severity and may be complicated by infection, acute exacerbation, cardiovascular events, or lung cancer [4-6]. The in-hospital mortality rate for patients admitted with an acute exacerbation is over $50 \%[7,8]$. Hence, many patients refuse endotracheal intubation when their respiratory function worsens. In general, when patients have signed do-not-intubate (DNI) requests, HFNC has been increasingly used to provide palliative care. However, there is little evidence on the efficacy of end-of-life HFNC in patients with ILD.

This study aimed to assess the efficacy and tolerability of HFNC in patients with hypoxemic respiratory failure associated with ILD who had DNI orders by retrospectively comparing a series of such patients treated with either HFNC or NPPV.

\section{Methods}

\section{Study Design and Data Source}

This was a single-center, retrospective, observational study at Seirei Mikatahara General Hospital, Japan. All data were extracted from clinical records. The retrospective analysis of data was approved by the ethics board of Seirei Mikatahara General Hospital (approval No. 17-05). Informed consent was based on the choice to opt out on the website.

\section{Patients}

The medical records of patients admitted to the Department of Respiratory Medicine, Seirei Mikatahara General Hospital, between April 1, 2010, and February 28, 2017, were reviewed to select patients matching the following inclusion criteria: (1) age $\geq 18$ years; (2) a diagnosis of IPF, other idiopathic interstitial pneumonia (IIP), connective tissue disease-related interstitial pneumonia, chronic hypersensitivity pneumonitis, or sarcoidosis-related interstitial pneumonia; (3) the use of either HFNC or NPPV for hypoxic respiratory failure associated with the ILD; and (4) a decision to forego intubation such that mechanical ventilation was not used. In IIP cases without pathological evaluation, we used the eligibility criteria based on chest high-resolution computed tomography (HRCT) in the INPULSIS trials [9]. Those who met the criteria were defined as IPF, and those who did not meet the criteria were defined as non-IPF IIP. An experienced respiratory physician and a radiologist reviewed HRCT films and evaluated the HRCT findings. Patients who were switched from conventional oxygen therapy to HFNC were included in the HFNC group, and those who were switched from conventional oxygen therapy to NPPV were included in the NPPV group. HFNC was delivered using Nasal High Flow (Fisher \& Paykel Healthcare, Auckland, New Zealand), and NPPV was delivered using BiPAP Vision and V60 (Philips Respironics, Carlsbad, CA, USA). The choice of HFNC or NPPV and the settings were determined by each attending physician.

\section{Patient Characteristics}

The following patient characteristics were analyzed: age, sex, type of ILD, long-term oxygen therapy before admission, any cancer diagnosis, etiology of respiratory failure (by the attending physician's assessment), the $\mathrm{PaO}_{2}$ /fraction of inspiratory oxygen (P/F) ratio chosen, initial oxygen flow rates of HFNC, initial mode of NPPV, use of sustained sedation with opioids or midazolam, length of hospital stay, and duration of HFNC of NPPV use. We calculated the GenderAge-Physiology (GAP) score of patients who had undergone pulmonary function tests within 1 year before death [10].

\section{Outcome Measures}

The outcome measures were rates of 30-day survival after beginning HFNC or NPPV, in-hospital mortality, temporary interruption at the patient's request (we did not include interruptions for taking meals), discontinuation at the patient's request, as well as adverse events, respiratory rate, changes in the dyspnea scale before and after starting HFNC or NPPV, oral intake, and the patient's ability to converse with family or caregivers at the end of life.

The Japanese version of the Support Team Assessment Schedule (STAS-J) score was used as the dyspnea scale [11]. Information regarding the day of the patient's last meal and of the final conversation, adverse events, and interruptions or discontinuation of oxygen therapy were collected from the clinical records. To assess changes in the respiratory rate and dyspnea scale score, the pretreatment (i.e., the last value before beginning HFNC or NPPV) and posttreatment (i.e., first values recorded after beginning HFNC or NPPV) values were compared. To evaluate oral intake and communication ability in patients who died in the hospital, we determined the number of days from the last meal to death and from the last conversation to death.

\section{Statistical Analysis}

We summarized the patients' baseline characteristics using percentages for categorical variables and medians and interquartile ranges for continuous variables. The nonparametric MannWhitney $U$ test was used to analyze continuous variables and Fisher's exact test for categorical variables. A paired $t$ test was used to compare 2 continuous variables that corresponded. Survival curves were plotted using the Kaplan-Meier method. The log-rank test was used to compare differences in survival. To determine significant differences, a two-sided test was used, and the significance level was $p<0.05$. All statistical analyses were performed using EZR, version 1.35 (Saitama Medical Center, Jichi Medical University, Saitama, Japan) [12]. 


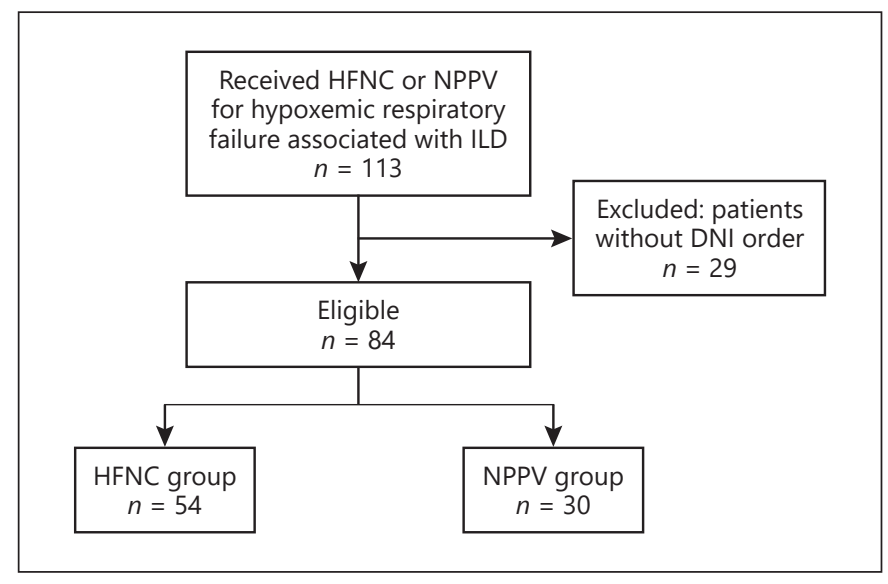

Fig. 1. Diagram of patient flow in the study. HFNC, high-flow nasal cannula; NPPV, noninvasive positive pressure ventilation; ILD, interstitial lung disease; DNI, do not intubate.

\section{Results}

\section{Patient Characteristics}

Between April 2010 and February 2017, HFNC or NPPV was used in 113 patients with hypoxic respiratory failure associated with ILD. We excluded 29 patients without DNI orders, leaving 84 patients for analysis; 54 in the HFNC group and 30 in the NPPV group (Fig. 1).

The 2 groups were equivalent in terms of age, sex, type of ILD, GAP scores, use of long-term oxygen therapy, a diagnosis of cancer, etiology of the deterioration in respiratory function, and $\mathrm{P} / \mathrm{F}$ ratio at the switch from conventional therapy to HFNC or NPPV. The median of the initial oxygen flow rate of HFNC was $40 \mathrm{~L} / \mathrm{min}$ (range, 30 $50)$. In the NPPV group, 28 patients (93.3\%) initially used the spontaneous/timed mode, and 2 patients (6.7\%) used the continuous positive airway pressure mode. The median number of hospital days was 25.5 in the HFNC group and 30.5 in the NPPV group. Sustained sedation using opioids or midazolam was administered to 28 patients (51.9\%) in the HFNC group and to 17 patients (56.7\%) in the NPPV group. HFNC and NPPV were used for a median of 7 and 5 days, respectively (Table 1).

\section{Outcomes}

The 30-day survival rate was equivalent in the 2 groups (HFNC $31.5 \%$ vs. NPPV $30.0 \%$; $p=0.86$ ). The KaplanMeier curves are shown in Figure 2. The in-hospital mortality was 43 cases $(79.6 \%)$ in the HFNC group and 25 cases $(83.3 \%)$ in the NPPV group ( $p=0.78)$ (Table 2). The temporary interruption rate was significantly lower in the

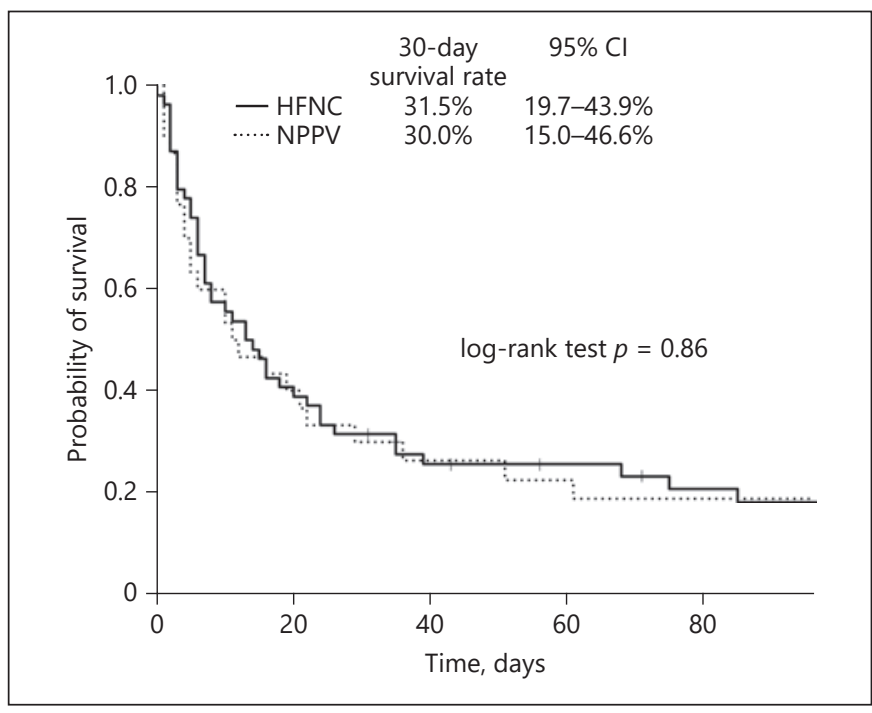

Fig. 2. Kaplan-Meier survival curves for patients with hypoxemic respiratory failure associated with interstitial lung disease treated with HFNC oxygen therapy or NPPV. HFNC, high-flow nasal cannula; NPPV, noninvasive positive pressure ventilation; $\mathrm{CI}$, confidence interval.

HFNC group ( 3.7 vs. $23.3 \% ; p=0.009$ ), as was the discontinuation rate ( 0 vs. $10 \% ; p=0.043$ ). Significantly fewer adverse events occurred in the HFNC group $(p=0.003)$ (Table 2). In the HFNC group, 1 patient had a nose bleed; in the NPPV group, 5 had skin damage, 1 had a gingival ulcer, and 1 had a pneumomediastinum.

In the HFNC group, a significant improvement in the respiratory rate was observed after beginning HFNC (pretreatment $28.0 \pm 7.0$ per min vs. posttreatment $23.8 \pm$ 4.3 per min; $p=0.0001$ ), whereas no significant change was observed in the NPPV group (pretreatment 31.2 \pm 8.1 per min vs. posttreatment $32.6 \pm 8.9$ per $\min ; p=0.343$ ). The STAS-J dyspnea scores did not change significantly between pre- and posttreatment in either group (Table 3 ). Among patients who died in the hospital, those with HFNC were significantly better able to eat before death (median, 2 days vs. 4 days in the NPPV group; $p=0.037$ ) and to converse before death (median, 1 day vs. 2 days; $p=0.042)$ (Table 2).

\section{Discussion}

This study retrospectively investigated the efficacy and tolerability of HFNC compared to NPPV for hypoxemic respiratory failure in patients with ILD who had DNI or- 
Table 1. Characteristics of patients with hypoxemic respiratory failure associated with ILD

\begin{tabular}{|c|c|c|c|}
\hline Characteristics & $\begin{array}{l}\text { HFNC group } \\
(n=54)\end{array}$ & $\begin{array}{l}\text { NPPV group } \\
(n=30)\end{array}$ & $p$ value \\
\hline Age, years & $78(72-82)$ & $79(71-84)$ & 0.89 \\
\hline Male sex & $38(70.4)$ & $23(76.7)$ & 0.62 \\
\hline Type of ILD & & & 0.64 \\
\hline IPF & $27(50.0)$ & $17(56.7)$ & \\
\hline Non-IPF IIP & $18(33.3)$ & $9(30.0)$ & \\
\hline CTD-IP & $7(13.0)$ & $3(10.0)$ & \\
\hline CHP & $2(3.7)$ & $0(0)$ & \\
\hline Sarcoidosis & $0(0)$ & $1(3.3)$ & \\
\hline LTOT, yes & $20(37)$ & $13(43.3)$ & 0.64 \\
\hline Cancer diagnosis, yes & $9(16.7)$ & $7(23.3)$ & 0.56 \\
\hline GAP score & $4.5(3-5)(n=20)$ & $4(3-6)(n=20)$ & 0.95 \\
\hline Etiology of respiratory failure & & & 0.27 \\
\hline Acute exacerbation & $33(61.1)$ & $19(63.3)$ & \\
\hline Respiratory infection & $14(25.9)$ & $5(16.7)$ & \\
\hline Heart failure & $6(11.1)$ & $2(6.7)$ & \\
\hline Exacerbation of chronic respiratory failure & $1(1.9)$ & $2(6.7)$ & \\
\hline Pulmonary embolism & $0(0)$ & $1(3.3)$ & \\
\hline Carcinomatous lymphangiosis & $0(0)$ & $1(3.3)$ & \\
\hline $\mathrm{P} / \mathrm{F}$ ratio at $\mathrm{HFNC} / \mathrm{NPPV}$ application & $100(79-117)$ & $126(80-176)$ & 0.25 \\
\hline Sustained sedation, yes & $28(51.8)$ & $17(56.7)$ & 0.82 \\
\hline Length of hospital stay, days & $25.5(11-49)$ & $30.5(14-42)$ & 0.83 \\
\hline Duration of HFNC/NPPV use, days & $7(3-15)$ & $5(3-11)$ & 0.22 \\
\hline
\end{tabular}

Each parameter is expressed as $n$ (\%) or median (interquartile range). Parameters in each group were compared using Fisher's exact test or Mann-Whitney U test. ILD, interstitial lung disease; IPF, idiopathic pulmonary fibrosis; non-IPF IIP, idiopathic interstitial pneumonia excluding idiopathic pulmonary fibrosis; CTD-IP, connective tissue disease-related interstitial pneumonia; CHP, chronic hypersensitivity pneumonitis; LTOT, longterm oxygen therapy; GAP, Gender-Age-Physiology; P/F, $\mathrm{PaO}_{2}$ /fraction of inspiratory oxygen; HFNC, high-flow nasal cannula oxygen therapy; NPPV, noninvasive positive pressure ventilation.

Table 2. Outcomes in patients with hypoxemic respiratory failure associated with interstitial lung disease

\begin{tabular}{llcc}
\hline Outcome & $\begin{array}{l}\text { HFNC group } \\
(n=54)\end{array}$ & $\begin{array}{l}\text { NPPV group } \\
(n=30)\end{array}$ & $p$ value \\
\hline In-hospital mortality & $43(79.6)$ & $25(83.3)$ & 0.78 \\
Temporary interruption at the patient's request & $2(3.7)$ & $7(23.3)$ & 0.009 \\
Discontinuation at the patient's request & $0(0)$ & $3(10.0)$ & 0.043 \\
Adverse events & $1(1.9)$ & $7(23.3)$ & 0.003 \\
Number of days from the last meal to death & $2(1-5)(n=43)$ & $4(2-8)(n=25)$ & 0.037 \\
Number of days from the last conversation to death & $1(1-2)(n=43)$ & $2(1-4)(n=25)$ & 0.042 \\
\hline
\end{tabular}

Each parameter is expressed as $n(\%)$ or median (interquartile range). Parameters in each group were compared using Fisher's exact test or Mann-Whitney $U$ test. HFNC, high-flow nasal cannula oxygen therapy; NPPV, noninvasive positive pressure ventilation. 
Table 3. Changes in respiratory rate and dyspnea scale scores before and after beginning HFNC or NPPV

\begin{tabular}{|c|c|c|c|c|c|c|}
\hline & \multicolumn{3}{|l|}{ HFNC } & \multicolumn{3}{|l|}{ NPPV } \\
\hline & pre-HFNC & post-HFNC & $p$ value & pre-NPPV & post-NPPV & $p$ value \\
\hline Respiratory rate, breaths/min & $28.0(7.0)$ & $23.8(4.3)$ & 0.0001 & $31.2(8.1)$ & $32.6(8.9)$ & 0.34 \\
\hline STAS-J dyspnea score & $1.14(0.72)$ & $0.90(0.57)$ & 0.07 & $1.37(0.69)$ & $1.30(0.82)$ & 0.69 \\
\hline
\end{tabular}

Each parameter is expressed as mean (standard deviation). Parameters in each group were compared with the paired $t$ test. HFNC, high-flow nasal cannula oxygen therapy; NPPV, noninvasive positive pressure ventilation; STAS-J, Japanese version of the Support Team Assessment Schedule.

ders. Our results revealed that HFNC was associated with survival equivalent to that with NPPV, but it was better tolerated than NPPV. Although based on only short-term evaluation, an immediate improvement in the respiratory rate was observed only in the HFNC group. In addition, HFNC allowed better oral intake and ability to converse until just before death.

ILD is a chronic progressive disease with a relentless downhill clinical course, so that, as the respiratory condition worsens, patients and their families very often decide to refuse life-prolonging endotracheal intubation. Curtis et al. [13] classified patients with acute respiratory failure treated with NPPV into 3 categories: (1) patients who desire full-life support without preset limits to the treatment; (2) patients who decline endotracheal intubation but accept other forms of life support; and (3) patients who decide in advance that they wish only symptom relief but no life-prolonging therapy. Patients with ILD who have DNI orders are, by definition, in either the second or third category, though those in the second category often change their preference to the third category, asking for comfort care only at some point in their clinical course.

HFNC is an oxygen therapy that supplies heated, humidified high-flow mixed oxygen to the upper respiratory tract through a large-caliber nasal cannula. This treatment allows accurate determination of the inhaled oxygen concentration [14]; flushes away the expired gas accumulated in the dead space of the upper and lower airways, thus preventing carbon dioxide retention [15]; has a positive end-expiratory pressure-like effect through the application of positive pressure in the exhalation phase [16]; involves less discomfort and is well tolerated because it provides sufficiently heated and humidified oxygen to relieve nasal cavity irritation [17]; and easily allows oral care, eating, and conversations. In recent years, the use of HFNC prior to NPPV in patients with DNI orders has increased because it does provide some degree

HFNC in Patients with ILD with DNI Orders of life support while remaining an acceptable palliative measure. However, little evidence is available regarding the efficacy of HFNC specifically for patients with ILD who require palliation at the end of life.

By contrast, several studies have reported the efficacy of NPPV for hypoxemic respiratory failure in patients with ILD $[18,19]$, including during palliative care. A randomized controlled trial showed improvement of dyspnea and a reduction in morphine use achieved by using NPPV in patients with solid cancers at the end of life [20]. A retrospective cohort study demonstrated that NPPV reduced the respiratory rate in patients with end-stage IPF [21]. The European Respiratory Society and American Society of Thoracic Diseases guidelines list NPPV as a means of palliative care for dyspneic patients [22]. However, NPPV with a total-face mask makes oral intake impossible, and conversation is quite difficult. Patients often refuse NPPV, fearing the discomfort experienced when wearing a mask. In fact, a relatively low acceptance rate of NPPV was observed in the randomized trial mentioned above [20].

Among patients with acute hypoxemic respiratory failure, the rates of intubation and of death are reportedly equivalent regardless of the prior use of HFNC, conventional oxygen therapy, or NPPV [1-3]. A prospective interventional study in which HFNC and NPPV were applied alternately in 14 patients with acute respiratory failure reported significantly better comfort with HFNC (on a 10 -point scale: HFNC, $2.7 \pm 1.8$ vs. NPPV, $5.4 \pm 3.1 ; p<$ $0.05)$, and the dyspnea score was significantly higher with HFNC (Borg scale: HFNC, $2.9 \pm 1.8$ vs. NPPV, $5.0 \pm 3.3$; $p<0.05)$ [23]. The FLORALI study also reported significantly better comfort in the HFNC group (100-mm visual analogue scale: HFNC, $29 \pm 26 \mathrm{~mm}$ vs. NPPV, $43 \pm$ $29 \mathrm{~mm} ; p<0.01)$ and better rate of dyspnea improvement (HFNC, $75.6 \%$ vs. NPPV, $58.3 \%$; $p<0.001$ ) [24]. These studies all indicate that HFNC is more comfortable and 
better tolerated than NPPV. Furthermore, it is expected to maintain a better QOL because it easily allows food intake and conversations. Our study also showed that HFNC permitted patients to eat and to converse until just before death. Two nationwide quantitative studies demonstrated that the ability to communicate with family and friends and to eat were commonly desired by many people at the end of life $[25,26]$, whereas tube feeding reportedly worsens QOL at that point [27].

To the best of our knowledge, only 2 reports have been published regarding the efficacy of HFNC for palliative care. A retrospective observational study reported that switching from conventional oxygen therapy to HFNC yielded a significant improvement in oxygenation and a decrease in respiratory rate in 50 patients with DNI orders, including 15 with IPF [28]. A report from the Memorial Sloan-Kettering Cancer Center analyzed the use of HFNC in 183 patients with cancer who had respiratory failure (including 101 with do-not-resuscitate orders). Both comfort and oxygen saturation improved in $41 \%$ of the patients and remained unchanged in $44 \%$. Only 2 patients refused HFNC [29]. Taken together, the available evidence indicates that HFNC provides an effective alternative to NPPV in the palliative care of dyspneic patients.

This study showed that survival with HFNC was comparable to that with NPPV, that it was quite tolerable, and that it has good potential for palliative use. Although our findings are potentially practice changing, there are limitations. First, this was a retrospective, single-center study. Second, NPPV and HFNC settings were not examined in detail. Third, the etiology of the respiratory failure in our patients was heterogeneous. In the future, the effect of HFNC should be analyzed for each cause of respiratory failure.

\section{Conclusion}

In patients with hypoxemic respiratory failure associated with ILD who had DNI orders, HFNC was associated with a survival rate equivalent to that of NPPV and was better tolerated than NPPV. Additionally, HFNC improved the respiratory rate and allowed patients to eat and converse until just before death. Our findings suggest that HFNC is an effective alternative to NPPV in these patients, although the results should be confirmed by a prospective randomized trial.

\section{Disclosure Statement}

The authors have no conflict of interest.

\section{References}

1 Monro-Somerville T, Sim M, Ruddy J, Vilas M, Gillies MA: The effect of high-flow nasal cannula oxygen therapy on mortality and intubation rate in acute respiratory failure: a systematic review and meta-analysis. Crit Care Med 2017;45:e449-e456.

2 Lee CC, Mankodi D, Shaharyar S, Ravindranathan S, Danckers M, Herscovici P, Moor M, Ferrer G: High flow nasal cannula versus conventional oxygen therapy and non-invasive ventilation in adults with acute hypoxemic respiratory failure: a systematic review. Respir Med 2016;121:100-108.

3 Nedel WL, Deutschendorf C, Moraes Rodrigues Filho E: High-flow nasal cannula in critically ill subjects with or at risk for respiratory failure: a systematic review and metaanalysis. Respir Care 2017;62:123-132.

4 Raghu G, Collard HR, Egan JJ, Martinez FJ, Behr J, Brown KK, Colby TV, Cordier JF, Flaherty KR, Lasky JA, Lynch DA, Ryu JH, Swigris JJ, Wells AU, Ancochea J, Bouros D, Carvalho C, Costabel U, Ebina M, Hansell DM, Johkoh T, Kim DS, King TE Jr, Kondoh Y, Myers J, Müller NL, Nicholson AG, Richeldi L, Selman M, Dudden RF, Griss BS, Protz- ko SL, Schünemann HJ; ATS/ERS/JRS/ALAT Committee on Idiopathic Pulmonary Fibrosis: An official ATS/ERS/JRS/ALAT statement: idiopathic pulmonary fibrosis: evidence-based guidelines for diagnosis and management. Am J Respir Crit Care Med 2011;183:788-824.

5 Travis WD, Costabel U, Hansell DM, King TE Jr, Lynch DA, Nicholson AG, Ryerson CJ, Ryu JH, Selman M, Wells AU, Behr J, Bouros D, Brown KK, Colby TV, Collard HR, Cordeiro CR, Cottin V, Crestani B, Drent M, Dudden RF, Egan J, Flaherty K, Hogaboam C, Inoue Y, Johkoh T, Kim DS, Kitaichi M, Loyd J, Martinez FJ, Myers J, Protzko S, Raghu G, Richeldi L, Sverzellati N, Swigris J, Valeyre D; ATS/ ERS Committee on Idiopathic Interstitial Pneumonias: An official American Thoracic Society/European Respiratory Society statement: update of the international multidisciplinary classification of the idiopathic interstitial pneumonias. Am J Respir Crit Care Med 2013;188:733-748.

6 Fernández Pérez ER, Daniels CE, Schroeder DR, St Sauver J, Hartman TE, Bartholmai BJ, Yi ES, Ryu JH: Incidence, prevalence, and clinical course of idiopathic pulmonary fibrosis: a population-based study. Chest 2010;137: 129-137.

7 Song JW, Hong SB, Lim CM, Koh Y, Kim DS: Acute exacerbation of idiopathic pulmonary fibrosis: incidence, risk factors and outcome. Eur Respir J 2011;37:356-363.

8 Kishaba T, Tamaki H, Shimaoka Y, Fukuyama H, Yamashiro S: Staging of acute exacerbation in patients with idiopathic pulmonary fibrosis. Lung 2014;192:141-149.

9 Richeldi L, du Bois RM, Raghu G, Azuma A, Brown KK, Costabel U, Cottin V, Flaherty KR, Hansell DM, Inoue Y, Kim DS, Kolb M, Nicholson AG, Noble PW, Selman M, Taniguchi H, Brun M, Le Maulf F, Girard M, Stowasser S, Schlenker-Herceg R, Disse B, Collard HR; INPULSIS Trial Investigators: Efficacy and safety of nintedanib in idiopathic pulmonary fibrosis. N Engl J Med 2014;370:2071-2082.

10 Ryerson CJ, Vittinghoff E, Ley B, Lee JS, Mooney JJ, Jones KD, Elicker BM, Wolters PJ, Koth LL, King TE Jr, Collard HR: Predicting survival across chronic interstitial lung disease: the ILD-GAP model. Chest 2014;145: 723-728. 
11 Miyashita M, Matoba K, Sasahara T, Kizawa Y, Maruguchi M, Abe M, Kawa M, Shima Y: Reliability and validity of the Japanese version of the Support Team Assessment Schedule (STAS-J). Palliat Support Care 2004;2:379385.

12 Kanda Y: Investigation of the freely available easy-to-use software "EZR" for medical statistics. Bone Marrow Transplant 2013;48:452458.

13 Curtis JR, Cook DJ, Sinuff T, White DB, Hill N, Keenan SP, Benditt JO, Kacmarek R, Kirchhoff KT, Levy MM; Society of Critical Care Medicine Palliative Noninvasive Positive Ventilation Task Force: Noninvasive positive pressure ventilation in critical and palliative care settings: understanding the goals of therapy. Crit Care Med 2007;35:932-939.

14 Ritchie JE, Williams AB, Gerard C, Hockey H: Evaluation of a humidified nasal high-flow oxygen system, using oxygraphy, capnography and measurement of upper airway pressures. Anaesth Intensive Care 2011;39:11031110.

15 Kernick J, Magarey J: What is the evidence for the use of high flow nasal cannula oxygen in adult patients admitted to critical care units? A systematic review. Aust Crit Care 2010;23: 53-70.

16 Parke RL, McGuinness SP: Pressures delivered by nasal high flow oxygen during all phases of the respiratory cycle. Respir Care 2013;58:1621-1624.

17 Roca O, Riera J, Torres F, Masclans JR: Highflow oxygen therapy in acute respiratory failure. Respir Care 2010;55:408-413.
18 Yokoyama T, Tsushima K, Yamamoto $\mathrm{H}$, Koizumi T, Kubo K: Potential benefits of early continuous positive pressure ventilation in patients with rapidly progressive interstitial pneumonia. Respirology 2012;17:315-321.

19 Güngör G, Tatar D, Saltürk C, Çimen P, Karakurt Z, Kirakli C, Adıgüzel N, Ediboglu Ö, Yılmaz H, Moçin ÖY, Balcı M, Yılmaz A: Why do patients with interstitial lung diseases fail in the ICU? A 2-center cohort study. Respir Care 2013;58:525-531.

20 Nava S, Ferrer M, Esquinas A, Scala R, Groff $\mathrm{P}$, Cosentini R, Guido D, Lin CH, Cuomo AM, Grassi M: Palliative use of non-invasive ventilation in end-of-life patients with solid tumours: a randomised feasibility trial. Lancet Oncol 2013;14:219-227.

21 Mollica C, Paone G, Conti V, Ceccarelli D, Schmid G, Mattia P, Perrone N, Petroianni A, Sebastiani A, Cecchini L, Orsetti R, Terzano C: Mechanical ventilation in patients with end-stage idiopathic pulmonary fibrosis. Respiration 2010;79:209-215.

22 Rochwerg B, Brochard L, Elliott MW, Hess D, Hill NS, Nava S, Navalesi P; Members of the Steering Committee; Antonelli M, Brozek J, Conti G, Ferrer M, Guntupalli K, Jaber S, Keenan S, Mancebo J, Mehta S, Raoof S; Members of the Task Force: Official ERS/ATS clinical practice guidelines: noninvasive ventilation for acute respiratory failure. Eur Respir J 2017;50.

23 Schwabbauer N, Berg B, Blumenstock G, Haap M, Hetzel J, Riessen R: Nasal high-flow oxygen therapy in patients with hypoxic respiratory failure: effect on functional and sub- jective respiratory parameters compared to conventional oxygen therapy and non-invasive ventilation (NIV). BMC Anesthesiol 2014; $14: 66$.

24 Frat JP, Thille AW, Mercat A, Girault C, Ragot S, Perbet S, Prat G, Boulain T, Morawiec E, Cottereau A, Devaquet J, Nseir S, Razazi K, Mira JP, Argaud L, Chakarian JC, Ricard JD, Wittebole X, Chevalier S, Herbland A, Fartoukh M, Constantin JM, Tonnelier JM, Pierrot M, Mathonnet A, Béduneau G, DelétageMétreau C, Richard JC, Brochard L, Robert R; FLORALI Study Group; REVA Network: High-flow oxygen through nasal cannula in acute hypoxemic respiratory failure. $\mathrm{N}$ Engl J Med 2015;372:2185-2196.

25 Hirai K, Miyashita M, Morita T, Sanjo M, Uchitomi Y: Good death in Japanese cancer care: a qualitative study. J Pain Symptom Manage 2006;31:140-147.

26 Miyashita M, Sanjo M, Morita T, Hirai K, Uchitomi Y: Good death in cancer care: a nationwide quantitative study. Ann Oncol 2007; 18:1090-1097.

27 Zhang B, Nilsson ME, Prigerson HG: Factors important to patients' quality of life at the end of life. Arch Intern Med 2012;172:1133-1142.

28 Peters SG, Holets SR, Gay PC: High-flow nasal cannula therapy in do-not-intubate patients with hypoxemic respiratory distress. Respir Care 2013;58:597-600.

29 Epstein AS, Hartridge-Lambert SK, Ramaker JS, Voigt LP, Portlock CS: Humidified highflow nasal oxygen utilization in patients with cancer at Memorial Sloan-Kettering Cancer Center. J Palliat Med 2011;14:835-839. 